\title{
A milestone in the new millennium
}

\author{
by Don Podlubny
}

The Environmental Training Centre (E.T.C.) located in Hinton, Alberta has much to celebrate as it enters the new millennium, marking its fortieth anniversary in the year 2000. Committed to excellence in learning, the E.T.C. has lead in the field of wildfire management training and excelled in specialized program development and support services.

Le "Environmental Training Centre (E.T.C.) situé à Hinton en Alberta, célèbre en grande pompe son entrée dans le nouveau millénaire, puisqu'il fête cette année son quarantième anniversaire. Le E.T.C. est un chef de file à la recherche de l'excellence dans l'apprentissage spécialisé dans la formation en matière de gestion des feux non-contrôlés, et excelle dans l'élaboration de programmes spécialisés et d'aide aux entreprises.

Developed in 1960 as a training centre for the Alberta Forest Service, the concept for the school originated almost a decade earlier, over 1200 kilometres from Hinton in the Kananaskis Valley. As technology advanced after the Second World War, it became apparent that forestry related training was necessary to keep up with the fast pace of development. As a result, in 1951 a ten week training course was created at the Kananaskis Forest Experiment Station in Seebe, Alberta.

Twenty rangers graduated from the first class, learning in a classroom that once served as a library for prisoners-of-war in the Kananaskis Valley. From this humble beginning, the training centre has evolved into a nationally and internationally recognized training facility, providing expertise in wildfire and forest management to professionals from across North America.

For nine years, ranger training occurred in the Kananaskis Valley. The classroom deteriorated as the course developed and grew in popularity and a new facility was required. Hinton was chosen as the new site, located $280 \mathrm{~km}$ west of Edmonton in the heart of Alberta's foothills and timber country. Construction of the new school began in 1959, and the Forest Technology School officially opened October 1, 1960.

The school facility and the courses offered expanded over the next few years, quickly gaining recognition and credibility among professionals in the forest industry. Additional short courses

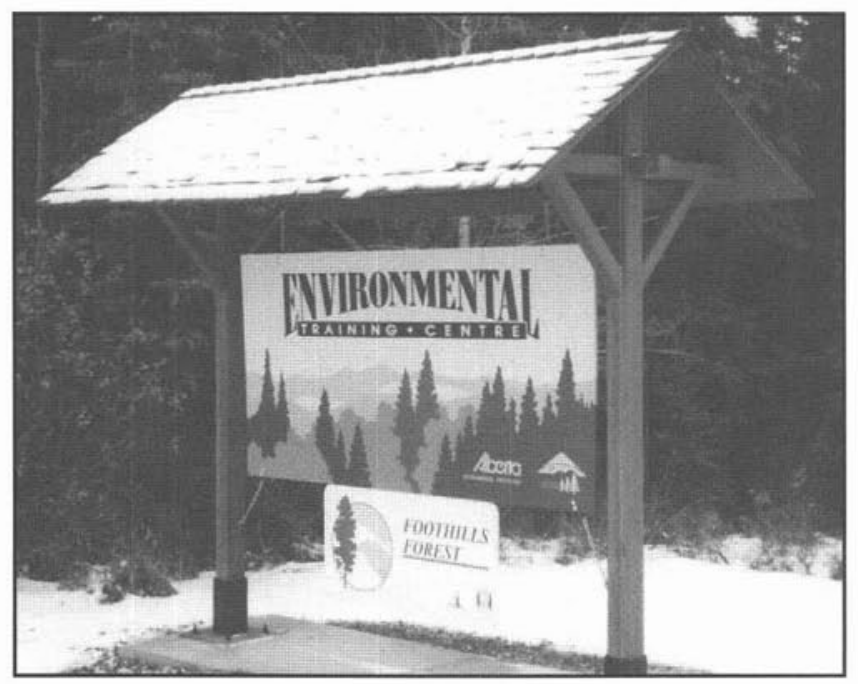

eventually grew to include a wide variety of fire control training, fireline positions, as well as fish and wildlife. In 1964, a two year Forest Technology course was introduced at the Forest Technology School through the Northern Alberta Institute of Technology (N.A.I.T.). [photo 2]

"The school in Hinton provided a practical and realistic

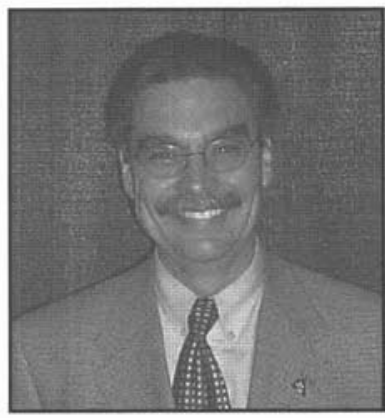
field training setting for students" recalls Ross Risvold, one of the earliest graduates from the program. "With the forest next door and such close access to the Cache Percott Forest we were able to take full advantage of the natural resources around us". Mr. Risvold was a member of the faculty at the E.T.C. for 20 years and acted as the head of the training centre for two years. As the Mayor of Hinton and one who is actively involved with the sustainability of resource based communities, he is fully aware of the importance of the forest industry and its vital link to communities such as Hinton. He also recognizes the important role the E.T.C. has played throughout its 40 years of history.

Today referred to as the Environmental Training Centre, specialized training and more than 51 different short courses are

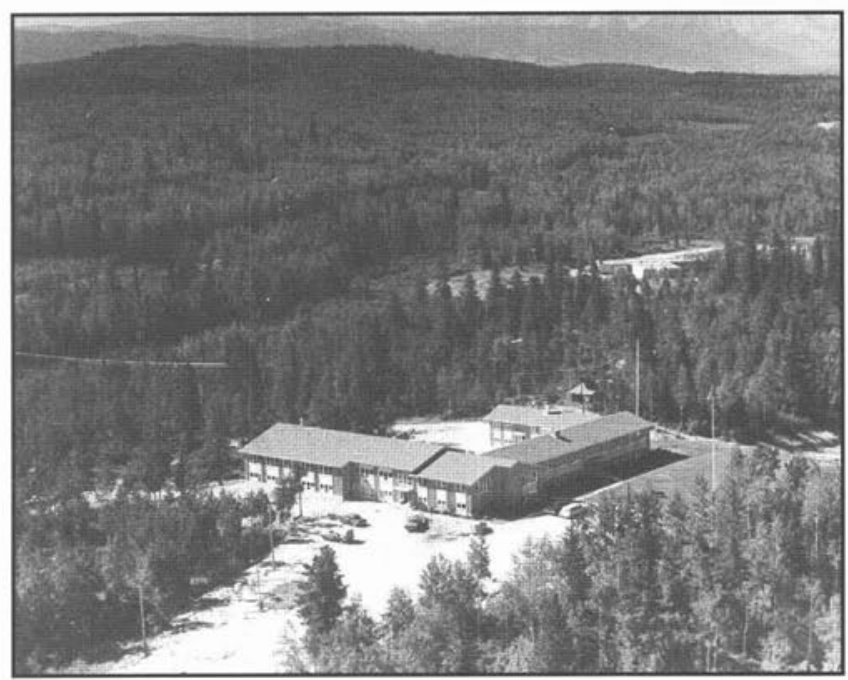




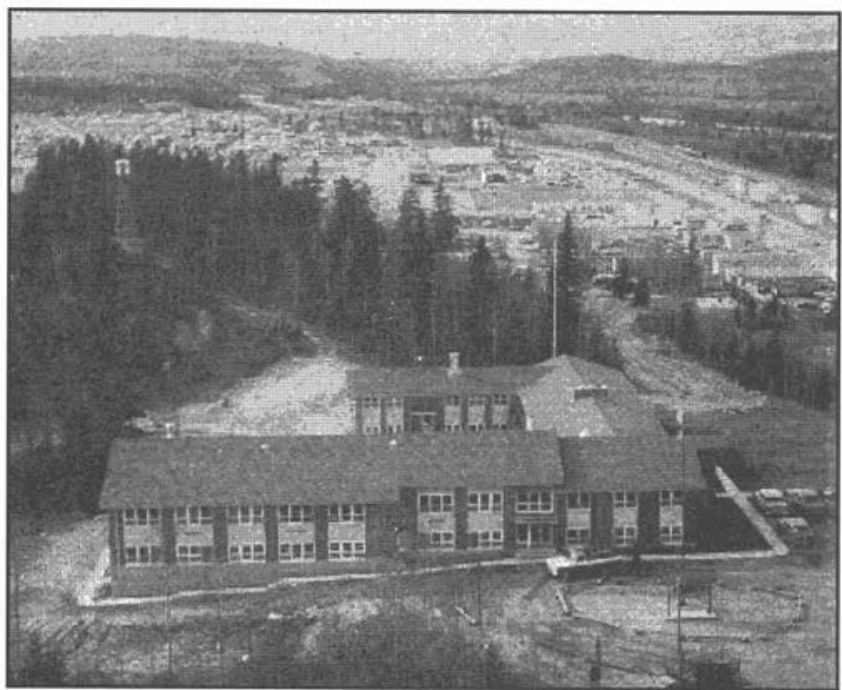

now offered to Alberta Environment personnel, special interest groups, agencies and the forest industry. On average, over 1,000 individuals from across the country and the United States attend the E.T.C. to participate in department and multiagency fire courses each year. In 1998, 8,200 people used the school and its facilities for training purposes and meetings relative to environmental concerns.

"A significant factor that has contributed to the E.T.C. program's success, is the collaboration between experienced and dedicated staff from both the Environmental Training Centre and the Land and Forest Service" says Don Podlubny, Director of the E.T.C. Another important element is the involvement and sharing of information from instructors across Canada as well as the United States.

A full range of Forest Management and Wildland Fire Management training provided throughout the year appeals to fire/forest and land management personnel with diverse experience and backgrounds. The variety of courses as well as some high tech tools developed at the E.T.C. help students learn, update their skills and prepare to meet the high standards associated with fire suppression in Alberta and other provinces. Realistic situations are simulated by a CD ROM program developed by staff from the E.T.C. that simulates fire situations and conditions for training purposes.

An additional tool is the Fire Simulator, a laser disc that was also developed by staff at the E.T.C. This software depicts a variety of wildfire situations ranging from fireline construction to the use of aircraft control of wildfires. The simulator also allows instructors to manipulate and control conditions and scenarios. "Both these tools provide real wildfire situations in a safe but realistic environment", states Terry VanNest, Manager of Training Operations.

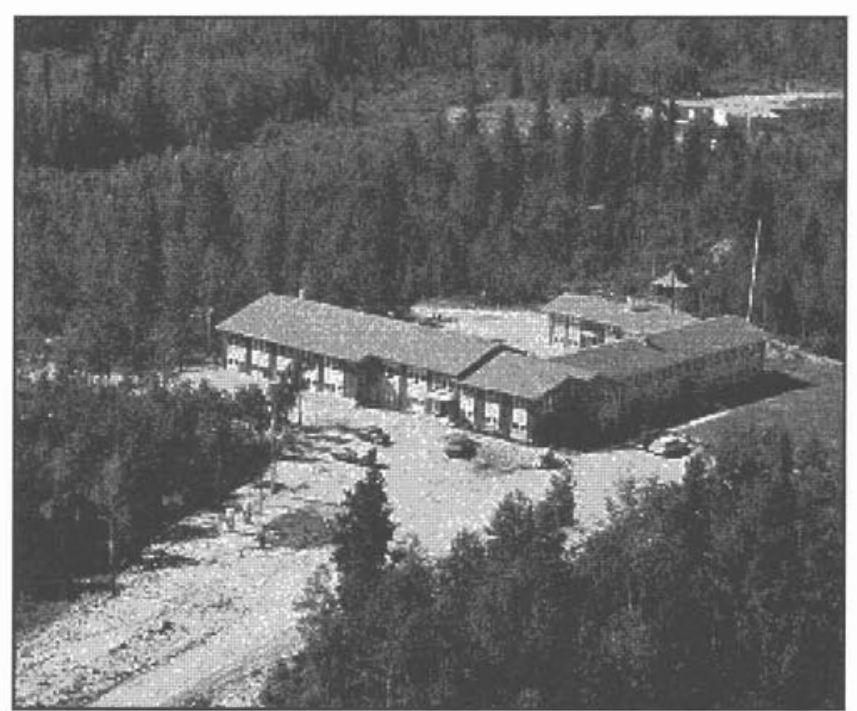

In addition to the wildland fire training, the E.T.C. diversified and now offers an intensive academic forest management training program. In 1998, the first class graduated from the Alberta Advanced Forest Management Institute (A.A.F.M.I.), a series of courses designed to meet the growing demand for additional training and information in a rapidly expanding forest industry. Its mandate is to enhance forest management in Alberta by providing opportunities for continuing education and personal development in the areas of silviculture and forest management planning.

The E.T.C. acknowledges the important role of Forest Technologists and Foresters, and recognises both as professionals in forest fire suppression and land management. The specialized training provided at the E.T.C. supports efforts to obtain continuing education and enhance existing skills of all forestry professionals. Efforts will also continue to increase integration of all aspects of natural resource management training, including aspects of watershed and wildlife management.

The year 2000 is a fitting year for the E.T.C. to mark forty years of achievement, as Hinton will be celebrating its designation as the Provincial Forest Capital for the year 2000. The E.T.C. will enter its $40^{\text {th }}$ year in the new millennium, proud of its history and accomplishments, and determined to provide continued excellence in forest management and wildland firefighting training.

For more information contact Don Podlubny at (780) 865-8200). The E.T.C. homepage can be viewed at www.gov.ab.calenv/reseduletcl. 